\title{
Article
}

\section{Total Phenolic, Anthocyanins HPLC-DAD-MS Determination and Antioxidant Capacity in Black Grape Skins and Blackberries: A Comparative Study}

\author{
Nadia Paun, Oana Romina Botoran (D) and Violeta-Carolina Niculescu *(D)
}

check for

updates

Citation: Paun, N.; Botoran, O.R.;

Niculescu, V.-C. Total Phenolic, Anthocyanins HPLC-DAD-MS Determination and Antioxidant Capacity in Black Grape Skins and Blackberries: A Comparative Study. Appl. Sci. 2022, 12, 936. https:// doi.org/10.3390/app12020936

Academic Editor:

Alessandra Durazzo

Received: 3 December 2021

Accepted: 14 January 2022

Published: 17 January 2022

Publisher's Note: MDPI stays neutral with regard to jurisdictional claims in published maps and institutional affiliations.

Copyright: (C) 2022 by the authors. Licensee MDPI, Basel, Switzerland. This article is an open access article distributed under the terms and conditions of the Creative Commons Attribution (CC BY) license (https:// creativecommons.org/licenses/by/ $4.0 /)$.
National Research and Development Institute for Cryogenic and Isotopic Technologies-ICSI Ramnicu Valcea, 4th Uzinei Street, 240050 Ramnicu Valcea, Romania; nadia.paun@icsi.ro (N.P.); oana.dinca@icsi.ro (O.R.B.)

* Correspondence: violeta.niculescu@icsi.ro

\begin{abstract}
Anthocyanins are flavonoids with an antioxidant effect. They are the pigments that give rich colours to berries, red onions, pomegranates, and grapes. In addition to acting as antioxidants and fighting free radicals, anthocyanins may offer anti-inflammatory, anti-viral, and anti-cancer benefits. Among various types of fruits, blackberries and grapes are distinguished by their rich content in polyphenols, including anthocyanins. The purpose of this study was the identification and quantification of the anthocyanins in black grape skins and blackberries, but also the determination of the total phenolic content and total antioxidant capacity. The grape skins and blackberry extracts were prepared by an ultrasound-assisted acidified ethanol and methanol extraction method, with the $80 \%$ methanol solution being the most effective. Alcoholic extracts of blackberries and grape skins were analysed by the HPLC-DAD-MS method. There were five glycosylated anthocyanin compounds in blackberries, eight glycosylated anthocyanins compounds, and seven fragments of anthocyanin derivatives in grape skins identified. It was concluded that the anthocyanin profile of blackberries and grapes revealed mainly anthocyanin monoglycosides and acetylglycosides. Cyanidin-3-glucoside was the main component (86.49\%) in blackberries, while, in the grape skins, the main component was delphinidin-3-O-glucoside (about 40.64\%). Principal component analysis (PCA) was carried out on the basis of the 13 identified compounds in order to separate the extracts and describe the anthocyanins characteristics of different groups, the findings being in agreement with the experimental results. Compared to methanol extracts, ethanol extracts showed higher antioxidant activity, being related to the total phenolic content for the blackberries. Overall, the obtained results indicated that the blackberries and grapes skins possessed a high antioxidant content, similar to other berries, highlighting their potential use as fresh functional foods or fruit-derived products.
\end{abstract}

Keywords: antioxidant capacity; anthocyanins; blackberries; grapes; polyphenols

\section{Introduction}

One of the most numerous and ubiquitous group of plant metabolites is represented by phenolic compounds constituting an integral part of the human diet. Beside their primary potent antioxidant activity, these compounds display a wide variety of biological functions, mainly related to the intervention in all stages of cancer development including initiation, promotion, progression, invasion, and metastasis [1,2]. Due to their phenolic content, many extracts from plants and fruits have been shown to reduce the oxidative stress-associated inflammatory diseases and cancer [3-5], and therefore it may exhibit synergy or additive biological effects due to the unique combination of polyphenols in the extracts prepared from various vegetal samples, using different extraction methods [6-8].

Anthocyanins, a group of natural pigments from the flavonoid family, are natural water-soluble compounds widely distributed in fruits and berries $[9,10]$. They are responsible for the blue, red, and purple colours of many fruits, flowers, and vegetables. These polyphenolic substances are glycosides of polyhydroxy- and polymethoxy-derivatives of 
2-phenylbenzopyrylium or the flavylium ion [11,12]. Anthocyanidins are known as the aglycones, being classified as 3-hydroxyanthocyanidins, 3-deoxyanthocyanidins, and Omethylated anthocyanidins, while anthocyanins can be found as anthocyanidin glycosides or acylated anthocyanins. The most common anthocyanidins are Cyanidin, Delphinidin, Malvidin, Pelargonidin, Peonidin and Petunidin (Figure 1). Acylated anthocyanins were also identified in plants, being classified into acryl anthocyanins, coumaroyl anthocyanins, caffeoyl anthocyanins, and malonyl anthocyanins [13].

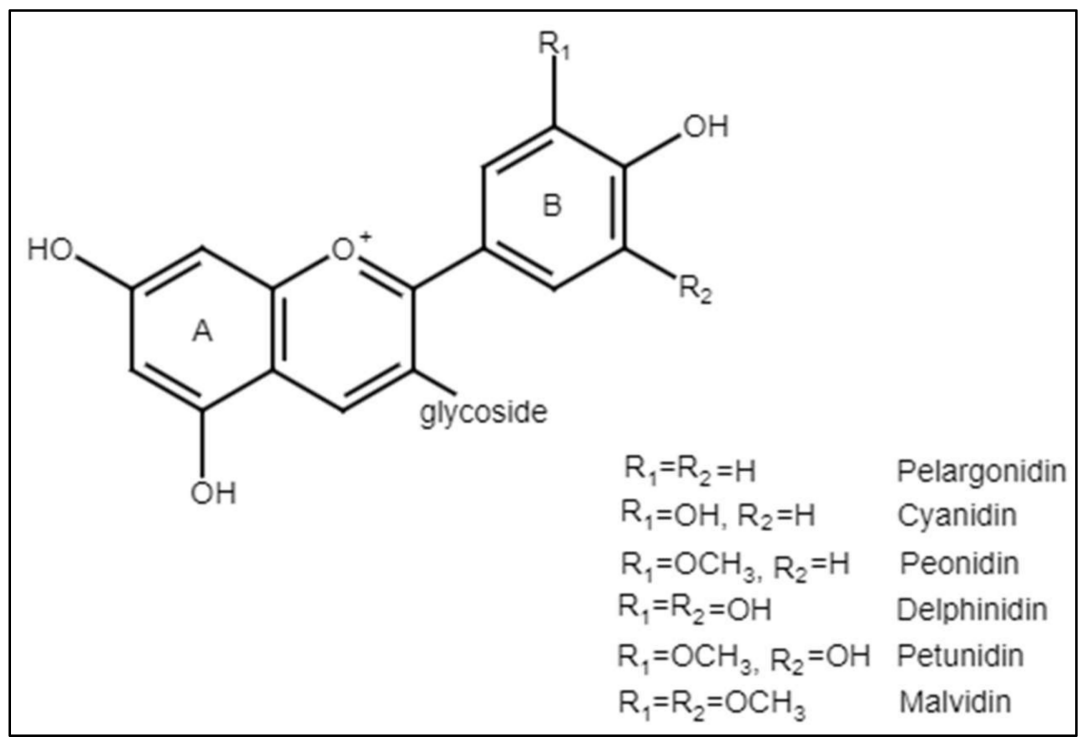

Figure 1. General structure for anthocyanin pigments (A and B rings were labelled).

The literature mentions that fruit-berries (such as blackberries, raspberries, blueberries, red or black berries, and red or black grapes) are rich in anthocyanins [14], natural antioxidants which annihilate action of free radicals, combat oxidative stress, and prevent the occurrence of neuro-degenerative diseases, cardiovascular disorders, and early aging $[15,16]$. Among different types of fruits, black grape skins and blackberries are distinguished for their high content in anthocyanin pigments [17,18]. Many studies suggest potential health benefits of anthocyanins $[16,18]$, but also their use in industry, as natural colorants [18].

For a long period of time, researchers have been investigating the total phenolic content of different berry fruits. Previous research has indicated that the amount and composition of bioactive compounds (e.g., flavonoids, total phenolics, and acids) in blackberry were primarily determined by the genotype of the plant [19]. It was observed that wild-grown blackberry fruits contained higher levels of total phenolics and antioxidant capacity than cultivated blackberry fruits [20]. An important element that influences the biochemical composition of blackberries is determined by the environment, which includes climate parameters (such as light intensity and temperature) but also agricultural factors (such as soil characteristics and plant development stage), among others [21,22]. It has also been shown in previous research that abiotic conditions have an impact on the quality of fruit, particularly on the useful components of different berry fruits [23]. In response to the above extrinsically conditions, the plant produces defence responses (molecular, physiochemical, physiological, and/or morphological), which include different genes activities that ultimately lead to the synthesis of secondary metabolites with antimicrobial and antioxidant properties [24]. Recently, fruits' antioxidant capacity has attracted much attention as a potentially valuable marker for determining fruit quality [25]. There is a direct relationship between antioxidant capacity and the availability of efficient oxygen radical scavengers (e.g., vitamin $C$ and phenolic compounds), which play a key role in managing oxidative reactions in the human body and possess anti-carcinogenic properties. Consequently, research studies regarding these attributes have been primarily motivated 
by the intent to explore new sources of natural antioxidants for use in food supplements or other food applications. In this regard, berry fruits are a very valuable resource due to their phytochemical composition, nutritional value, and antioxidant properties, all of which make it a valuable resource.

Lately, research targeted the analysis of the composition and antioxidant properties of different berry fruits (such as blackberries and grapes) in order to discover the optimal extraction methods of the active compounds. The conventional solvent extraction is the most used technique for the extraction of antioxidant compounds [26], although new nonconventional procedures have been applied as environmentally friendly options, such as microwave, ultrasound, or pressure-assisted extraction, applied alone or combined with the solvent method, in order to decrease energy and solvent demand [27]. This is also the case of the present study, in which the solvent extraction is combined with ultrasonication in order to improve the yields of extraction, but also to reduce the procedure requirements in terms of energy and solvent quantity. Practically, the combination of a classical method and a non-conventional one represents both a novelty and an advantage of this study.

Over the last years, the analytical techniques saw increased development, contributing to a better knowledge of polyphenols and anthocyanins. Once liquid chromatography mass spectrometry (LC/MS) and multiple mass spectrometry (MS/MS and MS ${ }^{n}$ ) techniques were developed in the 1990s, polyphenols structures began to be elucidated [28,29]. Various investigations on anthocyanins from grapes and wine have been developed since, making possible the better understanding of their involvement in wine making and aging $[14,15]$. Additionally, because of the widespread consumption of different berry fruits and the potential benefits they may possess related to human health and preventive medicine, studies such as the present approach are both significant and beneficial to the scientific community.

The objective of this work was the development of a reverse-phase, high-performance liquid chromatography (RP-HPLC) method coupled with diode array (DAD) and mass spectrometer (MS) detection in order to separate, identify, and quantify flavonoid glycosides from blackberries and black grape skins, but also to elucidate the relationship between antioxidant activity and the levels of total anthocyanin and total phenolic content.

\section{Materials and Methods}

\subsection{Raw Materials and Extraction Procedures}

Grapes (Othello) and wild blackberries fruit samples (Rubus Fruticosus) were collected from Iasi County, Moldavia region, Romania.

Fresh, ripe fruit samples were frozen and stored in the freezer at $-20 \pm 1{ }^{\circ} \mathrm{C}$ until use. Approximately $30 \mathrm{~g}$ of the frozen sample (grape skin and blackberry) were blended to produce a thick puree and then homogenised in $150 \mathrm{~mL}$ ethanol or methanol (Sigma Aldrich—Steinheim, Germany) containing $\mathrm{HCl}(0.01 \%)$ (Sigma Aldrich—Steinheim, Germany) using a shaker (Heidolph Unimax 1010, Heidolph Instruments GmbH \& Co.Schwabach, Germany) for dispersion. The samples were then placed in an ultrasonic bath (Elma S 60 H, Elma Hans Schmidbauer GmbH \& Co. KG, Singen, Germany) for 40 min at room temperature. The supernatants were collected after filtration and concentrated at $37^{\circ} \mathrm{C}$ under reduced pressure in a rotary evaporator (Buchi Rotavapor R-100, BUCHI Labortechnik AG, Flawil, Switzerland). The concentrate extracts were resuspended in ultrapure water produced with a Milli-Q Millipore system (Bedford, MA, USA) in order to obtain stock solutions, and then they were stored at $-20{ }^{\circ} \mathrm{C}$ for further characterization. The grape skins and blackberries puree was used to prepare various extracts with different solvent combinations of ultrapure water-methanol or ethanol (acidified with $0.01 \% \mathrm{HCl}$ $v / v$ ) to investigate the influence of the solvent on the properties of the extracts. Briefly, $10 \mathrm{~g}$ of puree were mixed with $50 \mathrm{~mL}$ of extraction solvent. The water-methanol or ethanol (acidified with $0.01 \% \mathrm{HCl}$ ) ratios were: 100/0, 75/25, 50/50, 25/75, 0/100. These two solvents were selected due to some observed aspects: (i) most studies showed that methanol offered the best extraction solvent for polyphenols; (ii) ethanol was chosen because it is non-toxic and the extracts will be further used to evaluate their antiproliferative effect, the 
methanol being not an option for this kind of study; (iii) both solvents were compared in order to evaluate the degree of extraction; and (iv) they are cheap and easy to handle compared to other solvents (such as ethyl acetate) [30].

\subsection{Total Polyphenolic Content}

Total phenolic content was estimated using the Folin-Ciocalteu method for total phenolic [31]. Folin-Ciocalteu method determines -OH groups based on the fact that light absorption increases as the number of $-\mathrm{OH}$ groups in a sample increases. Phenolic compounds react with Folin-Ciocalteu's reagent only under basic conditions (adjusted by a sodium carbonate solution to $\mathrm{pH}=10$ ). Briefly, diluted samples were mixed with Folin-Ciocalteu reagent (0.1 N) (Sigma Aldrich-Steinheim, Germany) and then treated with a saturated solution of sodium carbonate (Merck-Darmstadt, Germany) to maintain the reaction $\mathrm{pH}$ at 10 . The absorbance was measured at $765 \mathrm{~nm}$ with a Specord $250 \mathrm{UV}-\mathrm{VIS}$ Spectrophotometer (Analytik Jena AG-Jena, Germany) after incubation for $2 \mathrm{~h}$ at room temperature. Total phenolic content was calculated as Gallic acid equivalent based on the standard curve with a Gallic acid standard prepared in corresponding conditions (Figure 2).

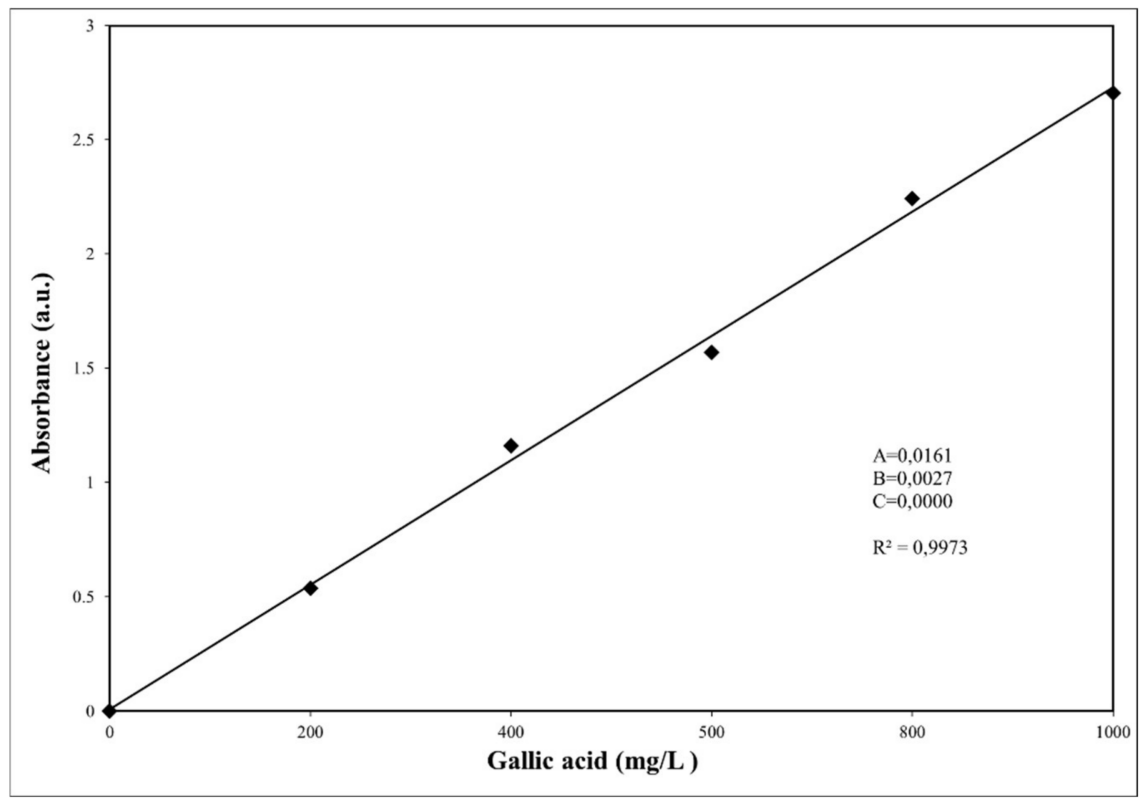

Figure 2. Folin-Ciocalteu Gallic Acid Standard Curve.

\subsection{HPLC-DAD-MS Method}

The fruits extracts were subjected to chromatographic separation using Agilent 1200 Series HPLC -DAD (Agilent Technologies-Santa Clara, CA, USA) system, using a reversedphase chromatography column (Zorbax 300 Extended-C18, $4.6 \times 150 \mathrm{~mm}, 5 \mathrm{~mm}$ ) (Agilent Technologies-Santa Clara, CA, USA), solvent degasser, binary pump, automatic injector (range of up to 100 samples), and UV-VIS detector DAD (diode array detector). To identify the anthocyanin extracts components, an Agilent 6500 Series Accurate-Mass Quadrupole Time-of-Flight (Q-TOF) LC/MS QLC/TOF MS was used (Agilent Technologies—Santa Clara, CA, USA). The extracts were separated at room temperature by injecting a volume of $10 \mu \mathrm{L}$ concentrated sample and filtered through a PTFE filter of $0.2 \mu \mathrm{m}$ (Millipore-Merck, Darmstadt, Germany), with a flow rate of $1 \mathrm{~mL} / \mathrm{min}$ (with splitter to 7:3 mass spectrometer) using several solvent systems and gradient programs. To separate and identify anthocyanins, it was used the following gradient program: isocratic $2 \% \mathrm{~B}, 0-7 \mathrm{~min}, 2-20 \% \mathrm{~B}$, 7-22 $\mathrm{min}, 20-30 \% \mathrm{~B}, 22-30 \mathrm{~min}, 30-40 \% \mathrm{~B}, 30-40 \mathrm{~min}, 40-2 \%$ B from $40-42 \mathrm{~min}$, and the column equilibration $2 \% \mathrm{~B}$ for another $5 \mathrm{~min}$, where $(\mathrm{A})$ is a mixture of ultrapure water produced with a Milli-Q Millipore system (Bedford, MA, USA): formic acid (99:1, v/v) (Sigma Aldrich-Steinheim, Germany), and (B) is a mixture of acetonitrile (Sigma Aldrich- 
Steinheim, Germany):solvent A (80:20, v/v). Solvents were filtered and degassed before use. The separation was monitored by a UV-VIS DAD detector at $520 \mathrm{~nm}$; an LC system was directly connected to the electrospray ionization source (ESI) mass spectrometry. Conditions selected in Q/TOF MS were: ESI in positive mode, drying gas flow $\left(\mathrm{N}_{2}\right) 6 \mathrm{~L} / \mathrm{min}$ gas temperature $220^{\circ} \mathrm{C}$; nebulisers pressure of $15 \mathrm{psig}$, capillary voltage $4200 \mathrm{~V}$; fragmentation voltage of $200 \mathrm{~V}$; and the compounds were investigated on the $m / z$ 100-3000. The data were processed using the MassHunter Workstation software.

\subsection{Monomeric Anthocyanin and Polymeric Colour Measurement}

Anthocyanin content was determined by the $\mathrm{pH}$ differential method based on the property of anthocyanin pigments to change the colour with $\mathrm{pH}$, described by Giusti and Wrolstad [32]. Total anthocyanin content was calculated as the content of cyanidin-3glucoside (MW $=449.2 \mathrm{~g} / \mathrm{mol}$, anthocyanin dominant in blackberries) by using a molar extinction coefficient of $26,900 \mathrm{~cm}^{-1} / \mathrm{mgL}$ and the content of delphinidin-3-glucoside (MW $=465.2 \mathrm{~g} / \mathrm{mol}$, anthocyanin dominant in grape skins) by using a molar extinction coefficient molecular $34,700 \mathrm{~cm}^{-1} / \mathrm{mgL}$ as follows:

$$
\text { Anthocyanin content }\left(\frac{\mathrm{mg}}{\mathrm{L}}\right)=(\mathrm{A} \times \mathrm{MW} \times \mathrm{DF} \times 1000) / \varepsilon \times 1
$$

where $\mathrm{A}=\left(\mathrm{A}_{510 \mathrm{~nm}}-\mathrm{A}_{700 \mathrm{~nm}}\right)_{\mathrm{pH} 1.0}-\left(\mathrm{A}_{510 \mathrm{~nm}}-\mathrm{A}_{700 \mathrm{~nm}}\right)_{\mathrm{pH} 4.5}, \mathrm{MW}=449.2$, and $\varepsilon=26,900$ for cyanidin-3-glucoside, respectively, and $\mathrm{MW}=465.2, \varepsilon=34,700$ for delphinidin-3-glucoside where $\mathrm{DF}=$ dilution factor.

Colour density and polymeric colour were calculated using absorption at 420, 510, and $700 \mathrm{~nm}$ with and without bisulphite treatment. The percentage of polymeric colour was determined by the ratio of polymerized colour to colour density.

\subsection{Trolox Equivalent Antioxidant Capacity (TEAC) Assay}

The antioxidant activities of the extracts were determined using TEAC assay. The TEAC assay for the extracts was carried out using a Specord 250 UV-Vis Spectrophotometer following a procedure from literature [33] with minor modification. ABTS ${ }^{+}{ }^{+}$was produced by reacting $7 \mathrm{mM}$ ABTS with $2.5 \mathrm{mM}$ potassium persulfate for $18 \mathrm{~h}$ in the dark at room temperature. The ABTS $\bullet^{+}$solution was diluted with water to an absorbance of 0.70 at $734 \mathrm{~nm}$ and equilibrated at $25{ }^{\circ} \mathrm{C}$. Samples of $20 \mu \mathrm{L}$ or Trolox standards in ethanol were added to $980 \mu \mathrm{L}$ of diluted $\mathrm{ABTS}^{+}{ }^{+}$solution. The absorbance readings were taken continuously for $7 \mathrm{~min}$ at $734 \mathrm{~nm}$ and $25^{\circ} \mathrm{C}$. The standard curve was generated based on the percentage of the blank absorbance by Trolox at 7 min versus Trolox concentration. The total antioxidant capacity (TAC) per gram of blackberry and grape skin concentrates was calculated as Trolox equivalent (TE), C ( $\mu \mathrm{M} \mathrm{TE})=(\%$ of inhibition-Intercept $) /$ Slope $)$, based on the percentage of inhibition of the blank absorbance by samples at $7 \mathrm{~min}$, using the following equation:

$$
\operatorname{TAC}\left(\frac{\mu \mathrm{mol} T \mathrm{TE}}{\text { g concentrate extract }}\right)=\frac{\mathrm{C}(\mu \mathrm{M} \mathrm{TE}) \times \text { Volume }(\mu \mathrm{L} \text { concentrate stock })}{\text { Weight }(\mathrm{g} \text { dried concentrate extract })}
$$

\subsection{Statistical Analysis}

The obtained results were statistically processed using XLSTAT Addinsoft 2014.5.03 software version (Addinsoft, New York, NY, USA). The correlation coefficients and their statistical significance were determined using Pearson's correlation analysis, while for identifying unsupervised grouping of the samples, principal component analysis (PCA) was performed.

\section{Results}

This study provides a comprehensive evaluation of GSE and BE from Romania-grown black grapes' skin and blackberries including extraction methods and characterization. 
Solvent extraction of phenolic compounds from fresh, dried, or freeze-dried fruit materials has been the most common method in fruit sample preparation. The solvents generally used were methanol, ethanol, acetone, water, and their mixtures. To obtain high yield of anthocyanins in the extract, solvents were usually mildly acidified to facilitate the liberation and solubilisation of anthocyanins from the fruit tissue and to stabilize anthocyanins as well. The relative recovery efficiency between solvents varied with different plant materials. For example, it was found that methanol was $20 \%$ more effective than ethanol and $73 \%$ more effective than water in recovering anthocyanins from grape pomace [34]. However, water was more effective in recovering anthocyanins from purple corn waste than acidified water or ethanol [32]. In addition to the solvent system, other factors such as temperature and time are important. It has been reported that elevated temperature improves extraction efficiency due to enhanced solubility and the diffusion rate of compounds into the solvent. However, high temperature accelerates anthocyanin degradation in the extraction process. A few extraction technologies, such as pressurized liquid extraction, have been developed to enable the rapid extraction of anthocyanins and other phenolics at high temperatures $\left(>50{ }^{\circ} \mathrm{C}\right)[35]$, and they were found to be successful in retarding anthocyanin degradation during processing. It was also found that ultrasound-assisted solvent extraction was more efficient for extracting anthocyanin than conventional solvent extraction due to the strong disruption of the fruit tissue under ultrasonic acoustic cavitation [36].

An ultrasound-assisted acidified ethanol and methanol extraction method was used for grape skin and blackberry extracts preparation. Total anthocyanin (TA) and phenolic content (TC), polymeric colour (PC), and the total antioxidant activity (TAC) of the grape skin and blackberry extracts are shown in Table 1.

Table 1. Composition and characterization of grape skin and blackberry extracts.

\begin{tabular}{ccccc}
\hline Raw Material & TC $(\mathbf{m g} / \mathbf{g})$ & $\begin{array}{c}\text { TA } \\
(\mathbf{m g} / \mathbf{g})\end{array}$ & $\begin{array}{c}\text { PC } \\
\mathbf{( \% )}\end{array}$ & $\begin{array}{c}\text { TAC } \\
(\boldsymbol{\mu m o l ~ T E} / \mathbf{g} \text { Extract) }\end{array}$ \\
\hline Blackberry puree $(50 \% \mathrm{EOH})$ & 25.83 & 18.80 & 15.88 & 264.27 \\
\hline Grape skin puree $(50 \% \mathrm{EOH})$ & 14.00 & 11.06 & 8.97 & 216.19 \\
\hline Blackberry puree $(80 \% \mathrm{MeOH})$ & 26.40 & 13.90 & 10.30 & 189.30 \\
\hline Grape skin puree $(80 \% \mathrm{MeOH})$ & 21.30 & 7.65 & 5.22 & 168.26 \\
\hline
\end{tabular}

Using the same extraction method, it was found that the total anthocyanin and phenolic content, polymeric colour, and total antioxidant activity were comparable between grape skin and blackberry extracts. It was found that blackberries had a higher content of both polyphenols and anthocyanins and significantly increased polymeric colour, both for extraction with ethanol and methanol, but the TAC values were higher for ethanol extracts than the methanol extracts. In addition, the percentage of polymeric colour was about $45 \%$ higher for blackberries and about $35 \%$ for ethanolic extracts, indicating that more polymeric browning products were extracted from blackberry than grape skin.

To investigate the effect of the extraction solvents with different ethanol to water ratios on the properties of the extracts, a series of GSE and BE were prepared from grape skin puree and blackberry puree using a solvent system with 0 to $100 \%$ ethanol content and two (one for grape skin and one for blackberry) extracts with $80 \%$ methanol content. As shown in Figure 3, the GSE and BE obtained using solvents with $25-70 \%$ ethanol contained about the same content in total polyphenols, the largest amount being obtained when $50 \%$ ethanol was used, while the same amount was obtained when $80 \%$ methanol was used for blackberries. For both blackberries and grapes, $80 \%$ methanol was the most effective, but in order to further study biological effects (such as anti-tumour effect), it is indicated to use ethanol, methanol being toxic for living beings. 


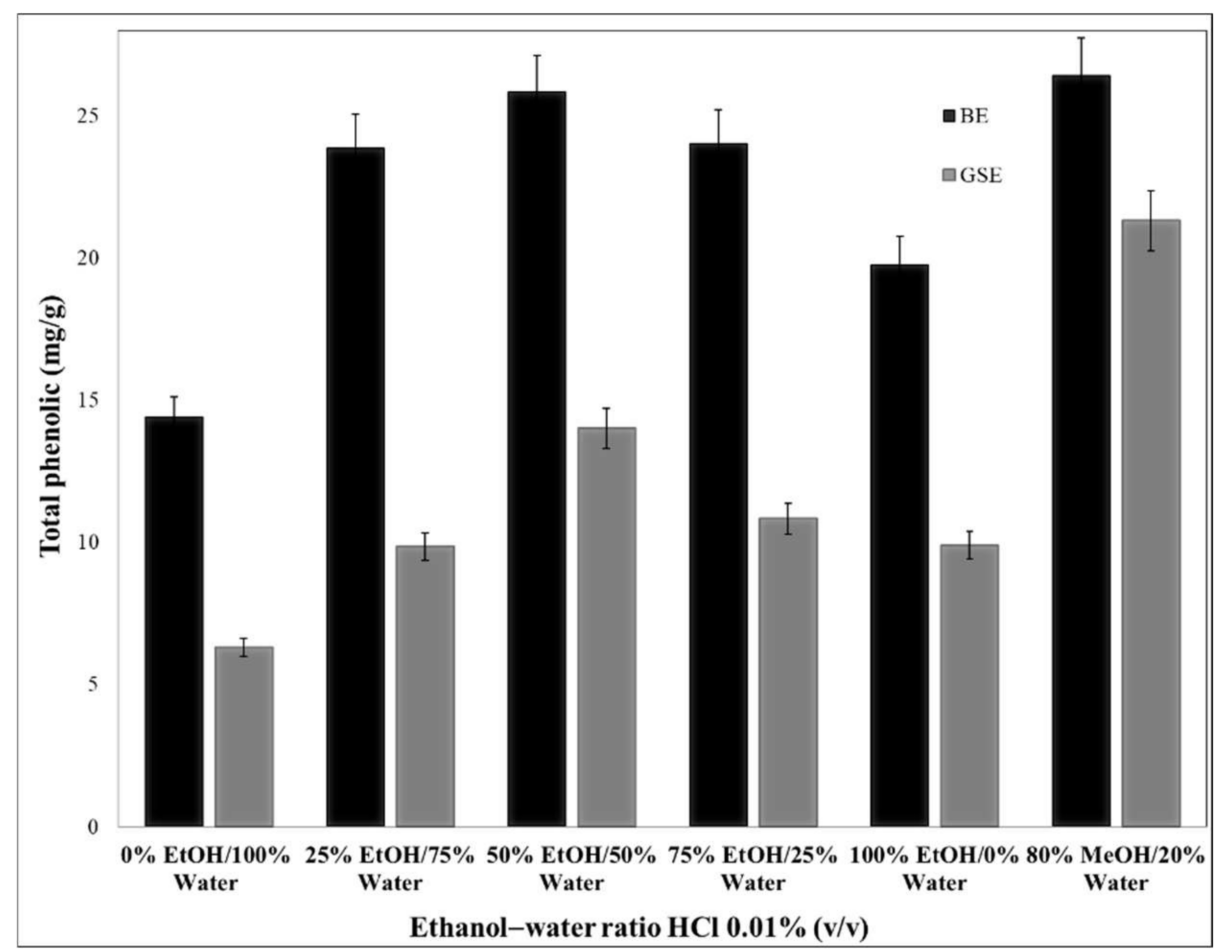

Figure 3. Variation in polyphenol content by solvent concentration.

In order to test this hypothesis, the GSE and BE different solvent extractions HPLC profiles were investigated. Figure 4 presents ESI/MS mass spectra for grape skin extract and the HPLC profile that showed thirteen picks, four of them being of high intensity (peaks 3, 4, 11, and 12), while the blackberry extracts profile showed six picks, one major (pick 1) and one unidentified (peak 6), as presented in Figure 5.

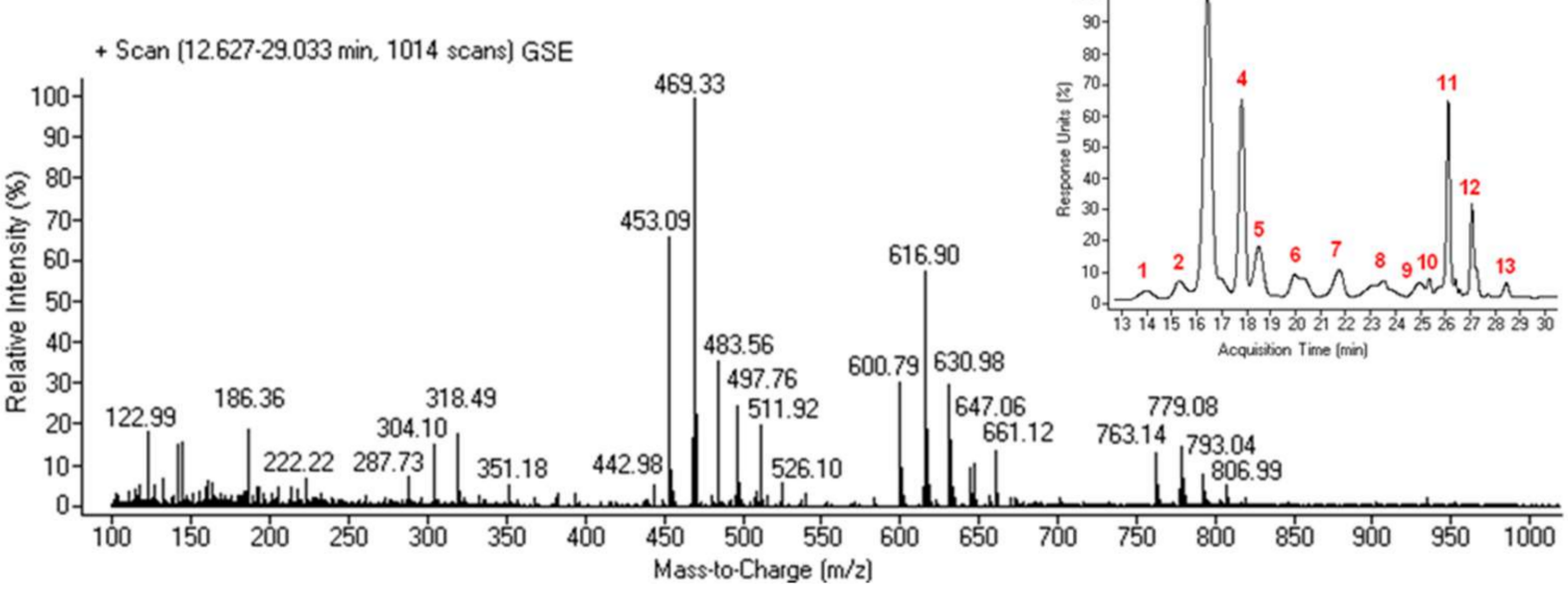

Figure 4. The total ESI/MS positive-ion mode analysis and HPLC profile of Othello grape skin extract. The red numbers represents the peak number so that it can be identified in Table 2 . 


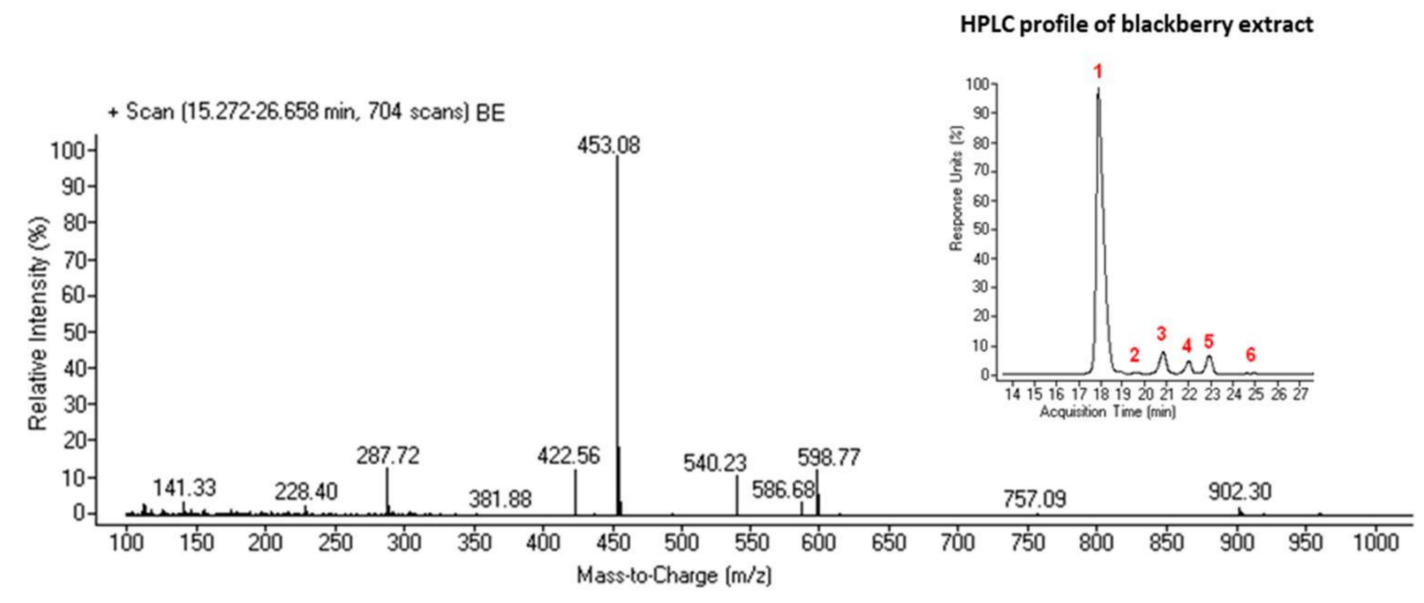

Figure 5. The total ESI/MS positive-ion mode analysis and HPLC profile of blackberry extract. The red number represents the peak number so that it can be identified in Table 2 .

Table 2. Peak assignment, retention time, mass special data, and percentage of grape skin and blackberry anthocyanins detected by HPLC and Electrospray Ionization-MS.

\begin{tabular}{|c|c|c|c|c|c|}
\hline Peak Number & $\begin{array}{c}\mathrm{RT} \\
(\mathrm{min})\end{array}$ & $m / z$ & $\begin{array}{l}\text { Mass Assignment } \\
\left(\mathbf{M}^{+} \text {Sau }[M+H]^{+}\right)\end{array}$ & Abv. * & Anthocyanin Content (\%) \\
\hline \multicolumn{6}{|c|}{ Othello grape skin extract } \\
\hline 1 & 13.9 & 633 & Malvidin-Delphinidin (MvDp_ fragment) & $\mathrm{M}_{1}$ & 1.87 \\
\hline 2 & 15.1 & 617 & Malvidin-Cyanidin (MvCy) fragment & $\mathrm{M}_{2}$ & 1.87 \\
\hline 3 & 16.2 & $469 / 303$ & Delphinidin-3-O-glucoside & $\mathrm{D}_{1}$ & 40.64 \\
\hline 4 & 17.6 & $453 / 287$ & Cyanidin-3-O-glucoside & $\mathrm{C}_{1}$ & 17.82 \\
\hline 5 & 18.2 & $453 / 287$ & Cyanidin-3-O-galactoside & $\mathrm{C}_{2}$ & 5.75 \\
\hline 6 & 19.7 & $467 / 303$ & Delphinidin-3-O-glucoside & $\mathrm{D}_{2}$ & 5.44 \\
\hline 7 & 21.5 & $511 / 303$ & Delphinidin-3-(6-O-acetylglucoside) & $\mathrm{D}_{3}$ & 4.25 \\
\hline 8 & 23.2 & $\begin{array}{l}779 / 287 \\
495\end{array}$ & $\begin{array}{l}\text { Malvidin-Cyanidin (MvCy) fragment + glucose }(\mathrm{G}) \\
\text { Malvidin-3-O-glucoside }\end{array}$ & $\mathrm{M}_{3}$ & 4.75 \\
\hline 9 & 24.7 & 763 & $\begin{array}{l}\text { Cyanidin-3-glucoside-Ethyl-coumaroyl } \\
\text { (Cy-3-glc-Ethyl-C) }\end{array}$ & $\mathrm{C}_{3}$ & 1.16 \\
\hline 10 & 25.1 & $\begin{array}{l}763 \\
617\end{array}$ & $\begin{array}{l}\text { Cyanidin-3-glucoside-Ethyl-coumaroyl } \\
\text { (Cy-3-glc-Ethyl-C) } \\
\text { Malvidin-Cyanidin (MvCy) fragment }\end{array}$ & $\mathrm{C}_{4}$ & 0.53 \\
\hline 11 & 25.8 & $\begin{array}{l}807 \\
617\end{array}$ & $\begin{array}{l}\text { Malvidin-3-glucoside-8- vinyl(epi)catechin } \\
\text { (Mv-3-glu-8-vinyl(epi)catechin) } \\
\text { Malvidin-Cyanidin (MvCy) fragment }\end{array}$ & $\mathrm{M}_{4}$ & 9.71 \\
\hline 12 & 26.8 & 601 & Malvidin-3-(6-O-acetylglucoside) pyruvate & $\mathrm{M}_{5}$ & 6.01 \\
\hline 13 & 28.1 & 645 & Malvidin-Petunidin fragment (MvPt) & $\mathrm{M}_{6}$ & 0.16 \\
\hline \multicolumn{6}{|c|}{ Blackberry extract } \\
\hline 1 & 18.0 & $453 / 287$ & Cyanidin-3-O-glucoside & $\mathrm{C}_{\mathrm{b} 1}$ & 86.49 \\
\hline 2 & 19.7 & $437 / 303$ & Delphinidin-3-xyloside & $\mathrm{D}_{\mathrm{b} 1}$ & 0.26 \\
\hline 3 & 20.7 & $422 / 287$ & Cyanidin-3-O-arabinoside & $\mathrm{C}_{\mathrm{b} 2}$ & 6.40 \\
\hline 4 & 21.4 & $540 / 287$ & Cyanidin-3-malonyl-glucoside & $\mathrm{C}_{\mathrm{b} 3}$ & 2.15 \\
\hline 5 & 22.9 & $598 / 287$ & Cyanidin-3-rutinoside & $\mathrm{C}_{\mathrm{b} 4}$ & 4.57 \\
\hline
\end{tabular}

* Abv.-abbreviation.

Peaks identification was carried out based on the molecular weight and structural information obtained from their MS spectra, in addition to their retention times from HPLC-UV-visible spectra (Table 2) [14]. 
Delphinidin-3-O-glucoside (peak 3, Figure 3) was the main component $(40.64 \%$ ) in GSE with the respective parent and daughter ion pairs ( $m / z$ 469/303), and Cyanidin-3-glucoside (peak 1, Figure 4 ) was the main component $(86.49 \%$ ) in BE with the respective parent and daughter ion pairs $(\mathrm{m} / \mathrm{z} 453 / 287)$. The other three major peaks (peak $4,17.82 \%$; peak 11 , $9.71 \%$; and peak $12,6.01 \%$ ) revealed the $m / z$ values of $453 / 287$, which were identified as cyanidin-3-glucoside 535/287, and 807, 617, 601 which were identified as malvidin derivatives. As shown in Table 2, all molar masses are higher for almost all compounds, e.g., molar mass for cyanidin-3-glycoside is 449 , and the mass spectrum shows 453 and the corresponding 287 for cyanidin. This may be due to the presence of deuterium atoms. The MS/MS spectrum of the ion at $m / z$, for example, shows ions at $m / z 186$ for grape skin extract and $m / z 228$ for blackberry extract. Substitution of a D for $H$ leads to the fragment ion at $m / z 186$ corresponding to $C_{2} \mathrm{HDO}$ loss, while the ion at $m / z 228$ could correspond to losses of $\mathrm{H}_{2} \mathrm{O}$. Fragmentations were definitively confirmed by accurate mass measurements.

In order to separate these extracts and describe the anthocyanins characteristics of different groups, a principal component analysis (PCA) was carried out on the basis of the 13 identified compounds. PCA was applied to the raw data in order to reduce the number of dimensions of the system. A total of four principal components with eigenvalues $>1$ was obtained, explaining $100 \%$ of the total variance for the Othello grape skin extract. PC1 and PC2 possessed relatively high percentages of variance (57.17 and $19.53 \%$, respectively). PC1 was mainly represented by delphinidin derivatives $\left(D_{1}, D_{2}\right.$, and $\left.D_{3}\right), M_{3}$ and $M_{4}$ malvidin derivatives, and Cyanidin-3-glucoside-ethyl-coumaroyl. PC2 consisted primarily of the $\mathrm{M}_{1}$, $\mathrm{C}_{4}, \mathrm{M}_{5}$, and $\mathrm{M}_{6}$ malvidin derivatives, the first two with negative PC2 values. Figure 6 show the distribution of samples along these two principal components as well as the component weights of anthocyanins. On these biplots we can visualise sample differences, positive or negative correlations between anthocyanins, and the relationships that may exist between some groups of extracts and specified anthocyanins.
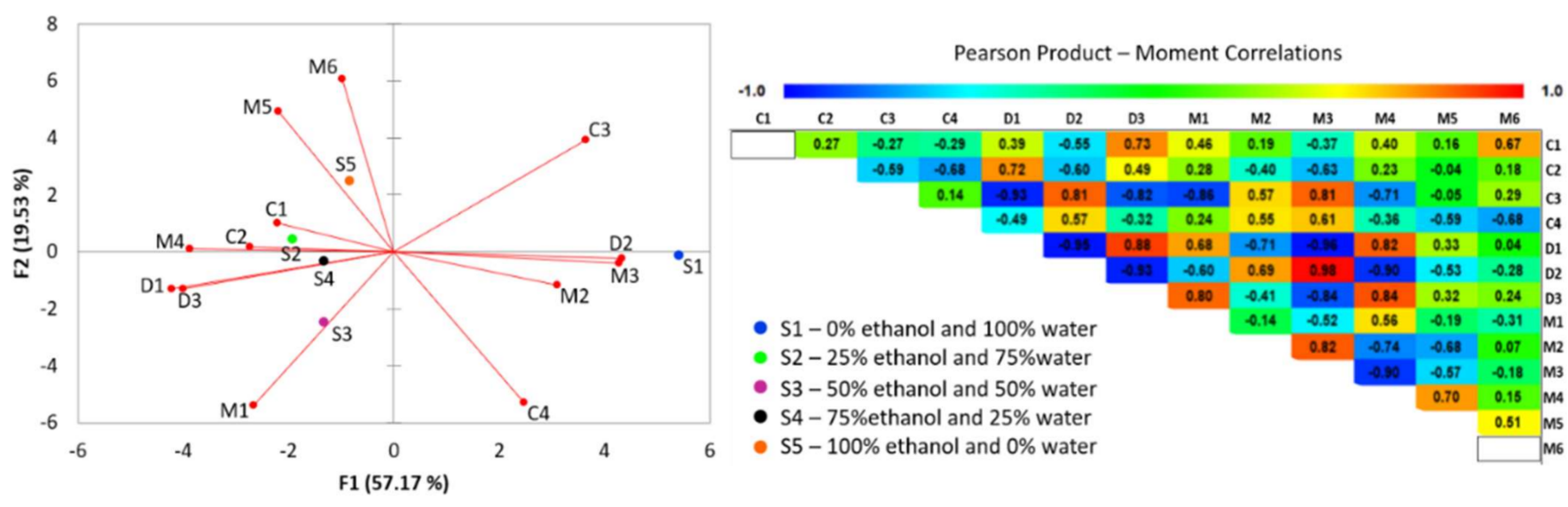

Figure 6. Distribution patterns of 13 variables and 5 different extracts belonging to the Othello grape samples in the two-dimensional space of PC1 and PC2 (the abbreviations of variables are presented in Table 2).

Thus, Figure 6 shows that PC1 allowed the clustering of extracts of S3, S4, and S2 because of their high relative concentrations in $\mathrm{M}_{1}, \mathrm{M}_{4}, \mathrm{M}_{5}, \mathrm{D}_{1}, \mathrm{D}_{2}$, and $\mathrm{D}_{3}$. On the opposite side of PC1, the S1 extract is located and could be related to the cyanidin derivatives. According to the Pearson analysis, the $C_{3}-D_{2}, C_{3}-M_{3}, D_{1}-D_{3}, D_{1}-D_{4}, D_{2}-M_{3}, D_{3}-M_{1}, D_{3}-M_{4}$, and $\mathrm{M}_{2}-\mathrm{M}_{3}$ variables groups were identified as strongly positive correlated, while the $\mathrm{C}_{3}$ $\mathrm{D}_{1}, \mathrm{C}_{3}-\mathrm{D}_{3}, \mathrm{C}_{3}-\mathrm{M}_{1}, \mathrm{D}_{1}-\mathrm{D}_{2}, \mathrm{D}_{1}-\mathrm{M}_{3}, \mathrm{D}_{2}-\mathrm{D}_{3}, \mathrm{D}_{2}-\mathrm{M}_{4}, \mathrm{D}_{3}-\mathrm{M}_{3}$, and $\mathrm{M}_{3}-\mathrm{M}_{4}$ groups present strong negative correlation. Among the five different extracts, S3, S4, and S2 are associated with the majority of this correlations, indicating that these mixtures are the most appropriate for the Othello grape seeds' anthocyanins extraction. These findings are in agreement with the results obtained in the investigation of the total polyphenols. The same principle was 
applied for the blackberry samples that have been subjected to the same types of extractions, observing that a good anthocyanin extraction yield was achieved for the $50-50 \%$ mixture.

For the determination of the antioxidant activity of grape skin and blackberry extracts (Table 1), the ABTS method was used. The assay was based on the relative ability of antioxidants to scavenge the cation radical ABTS $\bullet^{+}$[37].

The highest TAC ( $\mu \mathrm{mol}$ Trolox $\mathrm{g}^{-1} \mathrm{GSE}$ and/or BE) value was observed in the blackberry extract (264.27). Compared to methanol extracts, ethanol extracts showed higher antioxidant activity (264.27 toward 189.30 for blackberry and 216.19 toward 168.26 for grape skin). Equivalents of standards were calculated on the basis of standard regression line for gallic acid $\left(R^{2}=0.9973\right)$ and the standard regression line of Trolox was used to calculate TEAC (Trolox equivalent antioxidant capacity) $\left(R^{2}=0.9921\right)$. Percentage of inhibition was high in the case of both grape skin extract (Figure 7) and blackberry extract (Figure 8).

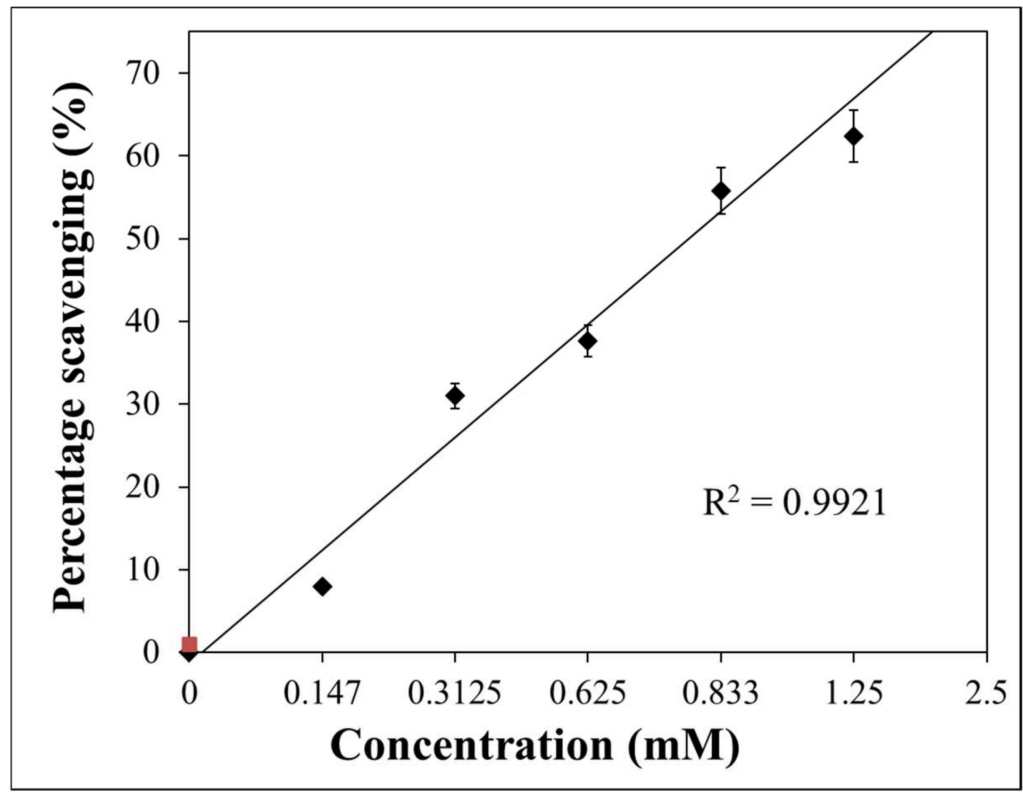

Figure 7. Percentage inhibition for grape skin extract in $\mathrm{ABTS}^{+}$scavenging activity.

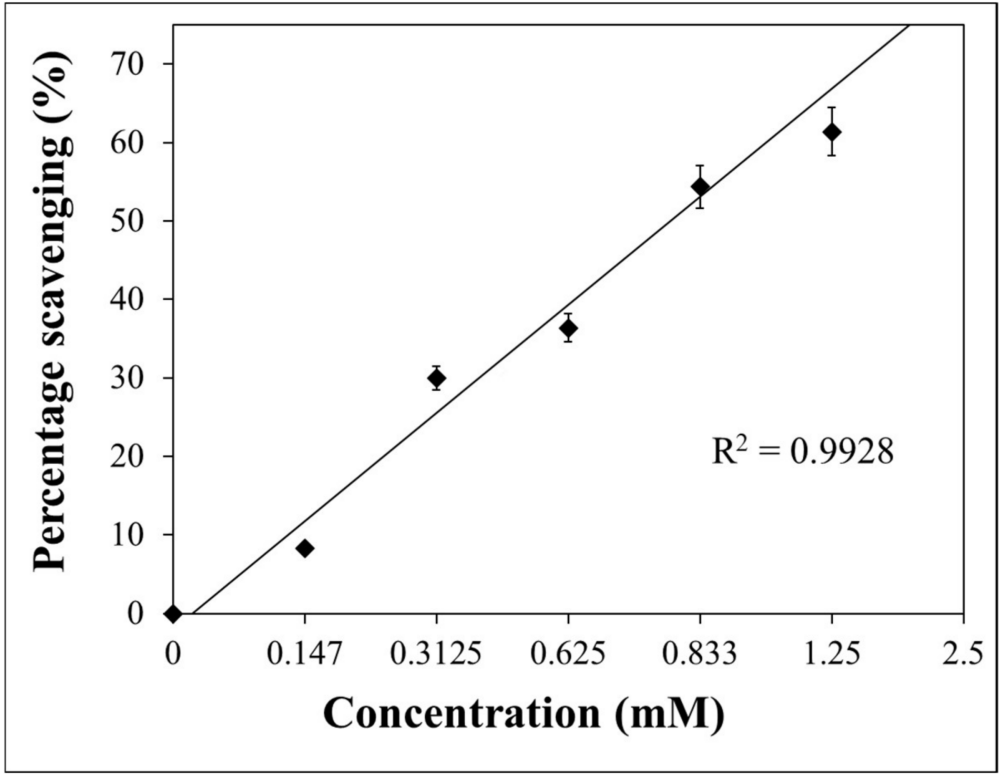

Figure 8. Percentage inhibition for blackberry extract in $\mathrm{ABTS}^{+}$scavenging activity. 
The TAC value can be considered as a stoichiometric number that can be correlated with a Trolox value of one. Indeed, many studies reported TAC values that depended not only on the phenolic content, but also on the phenolic compounds type and the reaction mechanisms [38]. This may suggest that TP can not be singularly used to explain the determined antioxidant activities of the extracts, which are in fact mixtures of various compounds with variable activities.

Figure 9 presents the correlations between TP, TA, PC, and TAC as a function of the extraction method.

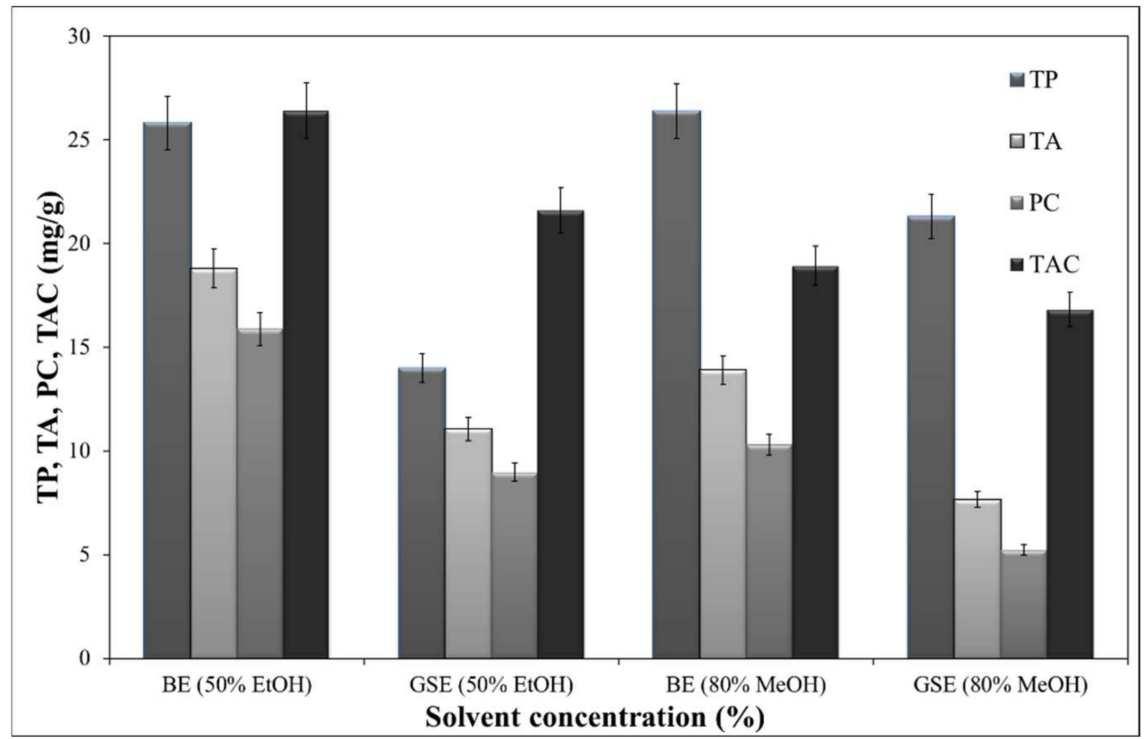

Figure 9. Correlation between TP, TA, PC, and TAC.

It can be observed that the highest TP values were obtained when $50 \%$ ethanol and $80 \%$ methanol were used as solvents for blackberries. At the same time, when $80 \%$ methanol was used, the TA, PC, and TAC decreased. In the case of black grape skins, the highest values of TP were observed when $80 \%$ methanol was used, but with a trade-off regarding the TA, PC, and TAC values. When $50 \%$ ethanol was used, the TP was lower, but it was observed increased values for TA, PC, and TAC.

Previous studies have reported that the higher phenolic content in the extracts resulted in higher antioxidant activity, which was in agreement with a positive correlation between TP and antioxidant activity $[39,40]$. So, in order to obtain the detail correlations between antioxidant capacity and the TPC, the correlation analyses were conducted (Table 3).

The significant correlations between the antioxidant properties and TP were found. The TP was highly associated with scavenging ability against ABTS $(r=0.977)$ for blackberries ethanolic extract. So, the data indicated that the phenolic compounds were considered responsible for effective antioxidant properties.

When compared with other methods [41,42], the developed HPLC method has one major advantage, allowing a proper separation of more anthocyanins from all berries extracts. This separation is also due to the selected extraction methods. Compared with other studies, it was observed that the ethanol and methanol extraction methods improved the antioxidant capacity of the grape skins, from $200 \mu \mathrm{M}$ Trolox/g extract [42] to $216 \mu \mathrm{M}$ TROLOX/g extract. Additionally, it was observed that the total phenolic content increased from $12.3 \mathrm{mg} \mathrm{GAE} / \mathrm{g}$ extract to $14 \mathrm{mg}$ GAE/g ethanolic extract and $21 \mathrm{mg}$ GAE/g methanolic extract. Despite there being a lack of information regarding the studied grapes (Othello type), it was demonstrated that they contain important amounts of polyphenols, and further studies should be performed in order to be able to use them as fresh functional foods or fruit-derived products. 
Table 3. Pearson's correlation coefficients for total phenolic content (TP) and antioxidant activity.

\begin{tabular}{|c|c|c|c|c|}
\hline Blackberries (50\% EOH) & TP & TA & PC & TAC \\
\hline TP & 1.000 & 0.728 & 0.615 & 0.977 \\
\hline TA & & 1.000 & 0.845 & 0.711 \\
\hline PC & & & 1.000 & 0.601 \\
\hline TAC & & & & 1.000 \\
\hline Grape skins $(50 \% \mathrm{EOH})$ & TP & TA & PC & TAC \\
\hline TP & 1.000 & 0.790 & 0.641 & 0.648 \\
\hline TA & & 1.000 & 0.811 & 0.512 \\
\hline PC & & & 1.000 & 0.415 \\
\hline TAC & & & & 1.000 \\
\hline Blackberries (80\% MeOH) & TP & TA & PC & TAC \\
\hline TP & 1.000 & 0.527 & 0.390 & 0.717 \\
\hline TA & & 1.000 & 0.741 & 0.734 \\
\hline PC & & & 1.000 & 0.544 \\
\hline TAC & & & & 1.000 \\
\hline Grape skins (80\% MeOH) & TP & TA & PC & TAC \\
\hline TP & 1.000 & 0.359 & 0.245 & 0.790 \\
\hline TA & & 1.000 & 0.682 & 0.455 \\
\hline PC & & & 1.000 & 0.310 \\
\hline TAC & & & & 1.000 \\
\hline
\end{tabular}

\section{Conclusions}

The purpose of this research was to obtain, study, and compare some red grape skin and blackberry extracts from Romania-grown fruits that contain high amounts of anthocyanins and polyphenols with high antioxidant activity potential. For grape skins and blackberries extracts, ultrasound-assisted acidified ethanol and methanol extraction methods were used. It was found that the total anthocyanin and phenolic content, polymeric colour and total antioxidant activity were comparable between grape skins and blackberries extracts. Compared to grape skins, blackberries had a higher content of both polyphenols and anthocyanins and significantly increased polymeric colour both for extraction with ethanol and methanol, but the TAC values were higher for ethanol extracts than the methanol extracts. In addition, the percentage of polymeric colour was about $45 \%$ higher for blackberries and about 35\% for grape skins extracts, indicating that more polymeric browning products were extracted from blackberries than grape skins.

The effect of the extraction solvents was investigated using different ethanol- ( 0 to $100 \%$ ethanol) to-water ratios on the properties of the extracts and, also, using $80 \%$ methanol content. In the range of $25-70 \%$ ethanol, the polyphenols amount was almost the same, the largest amount being obtained when $50 \%$ ethanol was used. For both blackberries and grapes, the methanol $80 \%$ has been shown to be the most effective, but to study the biological effects (such as anti-tumoral), the use of ethanol should be indicated, due to the toxicity of the methanol.

For the identification and quantification of the flavonoid glycosides from blackberries and black grape skins, a reverse phase high performance liquid chromatography (RP-HPLC) method was used coupled with diode array (DAD) and mass spectrometer (MS) detection. After the identification and quantification of the extracts, thirteen peaks for grape skins and five peaks for blackberries were obtained. Cyanidin-3-glucoside was the main component $(86.49 \%)$ in blackberries, in accordance with the literature [43]. In the grape skins the main component was delphinidin-3-O-glucoside (about 40.64\%). The obtained results indicated 
that the studied samples presented a high antioxidant content, similar to berries and other common fruits that have been reported as presenting a high antioxidant composition, this finding indicating their potential use as fresh functional foods or fruit-derived products (e.g., juices and fruit drinks). Because of their antioxidative potential, bioactive compounds from grape skin, framed as waste in some food industries, are not only critical elements of low-cost natural foods that are suitable for human consumption, but also have the potential to be valuable ingredients in the pharmaceutical industry.

Author Contributions: Conceptualization, N.P.; Data curation, O.R.B. and V.-C.N.; Formal analysis, N.P. and V.-C.N.; Funding acquisition, O.R.B.; Investigation, N.P. and V.-C.N.; Methodology, N.P., O.R.B. and V.-C.N.; Project administration, O.R.B.; Resources, O.R.B.; Software, O.R.B.; Supervision, N.P. and V.-C.N.; Validation, N.P., O.R.B. and V.-C.N.; Visualization, N.P. and V.-C.N.; Writingoriginal draft, N.P., O.R.B. and V.-C.N.; Writing-review and editing, N.P. and V.-C.N. All authors have read and agreed to the published version of the manuscript.

Funding: This work was financially supported by the project PN 191103 02-“Research on the variation trends specific to stable isotopes in different tree species: deepening the fractionation mechanisms and the chemical processes interconnected on the soil-water-plant chain"-Research Program "ICSI 4EE" financed by the Romanian Ministry of Research, Innovation and Digitalization.

Institutional Review Board Statement: Not applicable.

Informed Consent Statement: Not applicable.

Data Availability Statement: Not applicable.

Acknowledgments: This work was part of the project PN 191103 02_-"Research on the variation trends specific to stable isotopes in different tree species: deepening the fractionation mechanisms and the chemical processes interconnected on the soil-water-plant chain"-Research Program "ICSI $4 \mathrm{EE}$ " was financed by the Romanian Ministry of Research, Innovation and Digitalization. The authors are also grateful to Mihaela Silion from the "Petru Poni" Institute of Macromolecular Chemistry, Iasi, Romania for HPLC-DAD-MS determinations.

Conflicts of Interest: The authors declare that they have no known competing financial interest or personal relationship that could have appeared to influence the work reported in this paper.

\section{References}

1. Cháirez-Ramírez, M.H.; de la Cruz-López, K.G.; García-Carrancá, A. Polyphenols as Antitumor Agents Targeting Key Players in Cancer-Driving Signaling Pathways. Front. Pharmacol. 2021, 12, 710304. [CrossRef] [PubMed]

2. Briguglio, G.; Costa, C.; Pollicino, M.; Giambò, F.; Catania, S.; Fenga, C. Polyphenols in cancer prevention: New insights (Review). Int. J. Funct. Nutr. 2020, 1, 1. [CrossRef]

3. Mileo, A.M.; Nisticò, P.; Miccadei, S. Polyphenols: Immunomodulatory and Therapeutic Implication in Colorectal Cancer. Front. Immunol. 2019, 10, 729. [CrossRef] [PubMed]

4. Cory, H.; Passarelli, S.; Szeto, J.; Tamez, M.; Mattei, J. The Role of Polyphenols in Human Health and Food Systems: A Mini-Review. Front. Nutr. 2018, 5, 87. [CrossRef]

5. Yahfoufi, N.; Alsadi, N.; Jambi, M.; Matar, C. The Immunomodulatory and Anti-Inflammatory Role of Polyphenols. Nutrients 2018, 10, 1618. [CrossRef]

6. Oreopoulou, A.; Tsimogiannis, D.; Oreopoulou, V. Extraction of Polyphenols From Aromatic and Medicinal Plants: An Overview of the Methods and the Effect of Extraction Parameters. Polyphen. Plants 2019, 243-259. [CrossRef]

7. Sridhar, A.; Ponnuchamy, M.; Kumar, P.S.; Kapoor, A.; Vo, D.-V.N.; Prabhakar, S. Techniques and modeling of polyphenol extraction from food: A review. Environ. Chem. Lett. 2021, 19, 3409-3443. [CrossRef]

8. An, C.Y.; Hossain, M.; Alam, F.; Islam, A.; Khalil, I.; Alam, N.; Gan, S.H. Efficiency of Polyphenol Extraction from Artificial Honey Using C 18 Cartridges and Amberlite ${ }^{\circledR}$ XAD-2 Resin: A Comparative Study. J. Chem. 2016, 2016, 8356739. [CrossRef]

9. Kammerer, D. Anthocyanins. In Handbook on Natural Pigments in Food and Beverages: Industrial Applications for Improving Food Color; Woodhead Publishing: Sawston, UK, 2016; pp. 61-80. [CrossRef]

10. Khoo, H.E.; Azlan, A.; Tang, S.T.; Lim, S.M. Anthocyanidins and anthocyanins: Colored pigments as food, pharmaceutical ingredients, and the potential health benefits. Food Nutr. Res. 2017, 61, 1361779. [CrossRef] [PubMed]

11. De Pascual-Teresa, S.; Sánchez-Ballesta, M.T.; Garcia-Viguera, C.; Pascual-Teresa, S. Anthocyanins. In Natural Products: Phytochemistry, Botany and Metabolism of Alkaloids, Phenolics and Terpenes; Springer: Berlin/Heidelberg, Germany, 2013; pp. 1803-1819. [CrossRef] 
12. Paun, N.; Niculescu, V.; Tamaian, R.; Miricioiu, M. Functionalized Mesoporous Silica Nanoparticles as Novel Systems for Natural Anthocyanins Stability Enhancement. In Proceedings of the International Multidisciplinary Scientific GeoConference Surveying Geology and Mining Ecology Management, Albena, Bulgary, 29 June-5 July 2017; Volume 17.

13. Jordheim, M.; Calcott, K.; Gould, K.S.; Davies, K.M.; Schwinn, K.E.; Andersen, O.M. High concentrations of aromatic acylated anthocyanins found in cauline hairs in Plectranthus ciliates. Phytochemistry 2016, 128, 27-34. [CrossRef]

14. Flamini, R.; Mattivi, F.; De Rosso, M.; Arapitsas, P.; Bavaresco, L. Advanced Knowledge of Three Important Classes of Grape Phenolics: Anthocyanins, Stilbenes and Flavonols. Int. J. Mol. Sci. 2013, 14, 9651. [CrossRef]

15. Niculescu, V.-C.; Paun, N.; Ionete, R.-E. The Evolution of Polyphenols from Grapes to Wines. In Grapes and Wines-Advances in Production, Processing, Analysis and Valorization; Jordao, A.M., Cosme, F., Eds.; IntechOpen: London, UK, 2018. [CrossRef]

16. Krga, I.; Tamaian, R.; Mercier, S.; Boby, C.; Monfoulet, L.-E.; Glibetic, M.; Morand, C.; Milenkovic, D. Anthocyanins and their gut metabolites attenuate monocyte adhesion and transendothelial migration through nutrigenomic mechanisms regulating endothelial cell permeability. Free Radic. Biol. Med. 2018, 124, 364-379. [CrossRef] [PubMed]

17. Horbowicz, M.; Kosson, R.; Grzesiuk, A.; Dębski, H. Anthocyanins of Fruits and Vegetables-Their Occurrence, Analysis and Role in Human Nutrition. J. Fruit Ornam. Plant Res. 2008, 68, 5-22. [CrossRef]

18. Mattioli, R.; Francioso, A.; Mosca, L.; Silva, P. Anthocyanins: A Comprehensive Review of Their Chemical Properties and Health Effects on Cardiovascular and Neurodegenerative Diseases. Molecules 2020, 25, 3809. [CrossRef]

19. Gündoğdu, M.; Kan, T.; Canan, I. Bioactive and antioxidant characteristics of blackberry cultivars from East Anatolia. Turk. J. Agric. For. 2016, 40, 344-351. [CrossRef]

20. Milivojević, J.; Maksimović, V.; Nikolić, M.; Bogdanović, J.; Maletić, R.; Milatović, D. Chemical and antioxidant properties of cultivated and wild fragaria and rubus berries. J. Food Qual. 2011, 34, 1-9. [CrossRef]

21. Geana, E.-I.; Popescu, R.; Costinel, D.; Dinca, O.R.; Ionete, R.E.; Stefanescu, I.; Artem, V.; Bala, C. Classification of red wines using suitable markers coupled with multivariate statistic analysis. Food Chem. 2016, 192, 1015-1024. [CrossRef]

22. Ionete, R.E.; Stegarus, D.I.; Geana, E.I.; Botoran, O.R.; Sandru, C.; Miricioiu, M.G. Characterization and Classification of Romanian Wines by Origin A chemometric approach based on some metals and phenolic composition. Rev. Chim. 2019, 70, 3761-3768. [CrossRef]

23. Francini, A.; Pintado, M.M.; Manganaris, G.A.; Ferrante, A. Editorial: Bioactive Compounds Biosynthesis and Metabolism in Fruit and Vegetables. Front. Plant Sci. 2020, 11, 129. [CrossRef]

24. Artem, V.; Antoce, A.O.; Geana, E.-I.; Ionete, R.E. Study of the impact of vine cultivation technology on the Feteasca Neagra wine phenolic composition and antioxidant properties. J. Food Sci. Technol. 2021, 2021, 1-12. [CrossRef]

25. Donno, D.; Mellano, M.G.; De Biaggi, M.; Riondato, I.; Rakotoniaina, E.N.; Beccaro, G.L. New Findings in Prunus padus L. Fruits as a Source of Natural Compounds: Characterization of Metabolite Profiles and Preliminary Evaluation of Antioxidant Activity. Molecules 2018, 23, 725. [CrossRef]

26. Przybylska-Balcerek, A.; Szablewski, T.; Szwajkowska-Michałek, L.; Świerk, D.; Cegielska-Radziejewska, R.; Krejpcio, Z.; Suchowilska, E.; Tomczyk, Ł.; Stuper-Szablewska, K. Sambucus Nigra Extracts-Natural Antioxidants and Antimicrobial Compounds. Molecules 2021, 26, 2910. [CrossRef] [PubMed]

27. Hidalgo, G.-I.; Almajano, M.P. Red Fruits: Extraction of Antioxidants, Phenolic Content, and Radical Scavenging Determination: A Review. Antioxidants 2017, 6, 7. [CrossRef] [PubMed]

28. Niessen, W.; Tinke, A. Liquid chromatography-mass spectrometry General principles and instrumentation. J. Chromatogr. A 1995, 703, 37-57. [CrossRef]

29. Abian, J. The Coupling of Gas and Liquid Chromatography with Mass Spectrometry. J. Mass Spectrom. 1999, 34, 157-168. [CrossRef]

30. Do, Q.-D.; Angkawijaya, A.E.; Tran-Nguyen, P.L.; Huynh, L.H.; Soetaredjo, F.E.; Ismadji, S.; Ju, Y.-H. Effect of extraction solvent on total phenol content, total flavonoid content, and antioxidant activity of Limnophila aromatica. J. Food Drug Anal. 2014, 22, 296-302. [CrossRef] [PubMed]

31. Lamuela-Raventós, R.M. Folin-Ciocalteu method for the measurement of total phenolic content and antioxidant capacity. Meas. Antioxid. Act. Capacit. 2017, 107-117. [CrossRef]

32. Giusti, M.M.; Wrolstad, R.E. Characterization and measurement of anthocyanins by UV-Visible spectroscopy. Curr. Prot. Food Anal. Chem. 2001, F1.2.1-F1.2.13. [CrossRef]

33. Re, R.; Pellegrini, N.; Proteggente, A.; Pannala, A.; Yang, M.; Rice-Evans, C. Antioxidant activity applying an improved ABTS radical cation decolorization assay. Free Radic. Biol. Med. 1999, 26, 1231-1237. [CrossRef]

34. Metivier, R.P.; Francis, F.J.; Clydesdale, F.M. Solvent extraction of anthocyanins from wine pomace. J. Food Sci. 1980, 45, 1099-1100. [CrossRef]

35. Yuan, J.; Li, H.; Tao, W.; Han, Q.; Dong, H.; Zhang, J.; Jing, Y.; Wang, Y.; Xiong, Q.; Xu, T. An effective method for extracting anthocyanins from blueberry based on freeze-ultrasonic thawing technology. Ultrason. Sonochem. 2020, 68, 105192. [CrossRef] [PubMed]

36. Chen, F.; Sun, Y.; Zhao, G.; Liao, X.; Hu, X.; Wu, J.; Wang, Z. Optimization of ultrasound-assisted extraction of anthocyanins in red raspberries and identification of anthocyanins in extract using high-performance liquid chromatography-mass spectrometry. Ultrason. Sonochem. 2007, 14, 767-778. [CrossRef] [PubMed] 
37. Van den Berg, R.; Haenen, G.R.; van den Berg, H.; van der Vijgh, W.; Bast, A. The predictive value of the antioxidant capacity of structurally related flavonoids using the Trolox equivalent antioxidant capacity (TEAC) assay. Food Chem. 2000, 70, 391-395. [CrossRef]

38. Kim, J.-S. Antioxidant Activities of Selected Berries and Their Free, Esterified, and Insoluble-Bound Phenolic Acid Contents. Prev. Nutr. Food Sci. 2018, 23, 35-45. [CrossRef]

39. Juan, M.-Y.; Chou, C.-C. Enhancement of antioxidant activity, total phenolic and flavonoid content of black soybeans by solid state fermentation with Bacillus subtilis BCRC 14715. Food Microbiol. 2010, 27, 586-591. [CrossRef]

40. Xiao, Y.; Xing, G.; Rui, X.; Li, W.; Chen, X.; Jiang, M.; Dong, M. Enhancement of the antioxidant capacity of chickpeas by solid state fermentation with Cordyceps militaris SN-18. J. Funct. Foods 2014, 10, 210-222. [CrossRef]

41. Ştefănuţ, M.N.; Căta, A.; Pop, R.; Mosoarca, C.; Zamfir, A.D. Anthocyanins HPLC-DAD and MS Characterization, Total Phenolics, and Antioxidant Activity of Some Berries Extracts. Anal. Lett. 2011, 44, 2843-2855. [CrossRef]

42. Avram, S.; Danciu, C.; Pavel, I.Z.; Ceausu, R.A.; Avram, S.; Dehelean, C.; Raica, M. Polyphenols, Antioxidant Activity and Anti-angiogenic Potential of Red and White Grapes. Rev. Chim. 2016, 67, 382-385.

43. Gil Lee, S.; Vance, T.M.; Nam, T.G.; Kim, D.-O.; Koo, S.I.; Chun, O.K. Contribution of Anthocyanin Composition to Total Antioxidant Capacity of Berries. Plant Foods Hum. Nutr. 2015, 70, 427-432. [CrossRef] 